\title{
Phylogeography analysis and molecular evolution patterns of the nematode parasite Heligmosomum mixtum based on mitochondrial DNA sequences
}

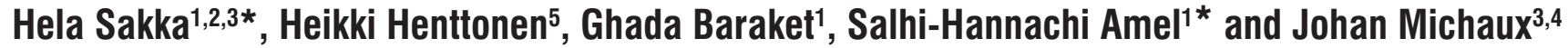 \\ ${ }^{1}$ Laboratoire de Génétique Moléculaire, Immunologie et Biotechnologie. Département de Biologie, faculté des Sciences \\ de Tunis. Unversité Tunis El Manar 2092 El Manar, Tunis, Tunisie; ${ }^{2}$ Faculté des Sciences de Bizerte, 7021 Zarzouna, Tunisie; \\ ${ }^{3}$ INRA, UMR CBGP 1062, Campus international de Baillarguet, CS 30016, F-34988 Montferrier-sur-Lez cedex, France; \\ ${ }^{4}$ Conservation Genetics Unit, University of Liège, Institute of Botany (Bat. 22) 4000 Liège, Belgium; \\ ${ }^{5}$ The Finnish Forest Research Institute Vantaa Research Unit, Vantaa Unit, Finland
}

\begin{abstract}
Mitochondrial DNA was explored to study phylogeography of the nematode parasite Heligmosomum mixtum and elucidate molecular evolution pattern of cytochrome $b$ gene. The size of cyt b gene ranged from $511 \mathrm{bp}$ to $591 \mathrm{bp}$ and the average of GC contents was $28.9 \%$. The overall transition/transversion ratio $\mathrm{R}$ was 5.773 indicating that the transitions are more frequent than transversion. The aligned sequences allowed identifying $54 \mathrm{mtDNA}$ haplotypes among the 119 examined individuals. The genetic divergence registered among the populations of $\mathrm{H}$. mixtum was low $(0.3 \%$ to $1.5 \%)$. Neighbor-joining and maximum Likelihood trees evidenced a huge polytomy and unstructured phylogeographic pattern among the studied populations. The demographic analyses tend to evidence a recent and rapid expansion of H. mixtum. Our results imply a positive selection and the genetic hitchhiking effect is unlikely. Parameters performed supported scenario of sweep selection and recent expansion of H.mixtum populations. Both positive selection and demographic histories have jointly contributed to the observed patterns of nucleotide diversity and haplotypes structure. The comparison of the phylogeographical pattern of $H$. mixtum with the one of its most common rodent host $M$. glareolus, confirmed a strong incongruence between the two species. These results strongly suggest that the parasite would not be specific to M. glareolus and that it would switch easily from one rodent species to another. The mitochondrial diversity seems to be unstructured with any biogeographic repartition of the variability and that the genetic structure of H. mixtum is probably associated with weak host specificity.
\end{abstract}

\section{Keywords}

Mitochondrial DNA, Cytochrome b gene, Phylogeography, Myodes glareolus, Nematode parasite, Heligmosomum mixtum

\section{Introduction}

Phylogeography is a field of research that studies the processes determining the geographical distribution of genetic lineages at the intra-specific or congeneric levels and is useful for detecting processes such as population subdivision, speciation events and ecological adaptation, and migration routes associated with past climatic changes (Avise 2000). However, the phylogeography of invertebrate taxa, particularly parasite species, was still poorly studied until recently (Wickström et al. 2003; Nieberding et al. 2004, 2005, 2008). Indeed, over the last few years, there has been increasing interest in investigating the dispersal abilities of invertebrates and micro-organisms (Nieberding et al. 2005). In this con- text, phylogeographical studies have been performed on parasites like nematodes and they enabled to understand whether and how the Pleistocene climatic fluctuations may have affected the genetic structure of parasite species. H. mixtum has a direct life-cycle (no intermediate host), it reproduces sexually with three free-living larval stages and a 4th, parasitic larval stage dwelling in the intestinal wall (Asakawa 1987). The micro-habitat of the adult is the lumen of the anterior small intestine (duodenum) (Haukisalmi and Henttonen 1993). The mating habits of H. mixtum are unknown, but polygamy is thought to prevail in nematodes (Haukisalmi et al. 1996). Its first larval stages are free and require 3 days to become infective. Host contamination occurs after ingestion of contaminated faeces. Adult parasites live in the intes- 
tine and produce eggs in the host faeces about 12 days after ingestion. Individuals in the free-living stage have no dispersal activity, so it seems that the gene flow in this species is determined by host movements (Goüy de Bellocq et al. 2002, 2003). The prevalence of H. mixtum (percentage of host infected) and its abundance (average number of parasites per host) on Myodes glareolus, are high, 45\% and 12 correspondingly (N'Zobadila 1994).

Myodes glareolus (Arvicolinae, Rodentia) is a forest dweller present throughout Europe since at least the middle Pleistocene (1.2 Ma) (Bauchau and Chaline 1987). The phylogeography and the post glacial colonization history of the bank vole have been extensively studied in Europe showing a complex phylogeographical structure (Deffontaine et al. 2005, 2009). The results revealed the presence of four Mediterranean (Basque, Spanish, Italian and Balkan) and three continental (western, eastern and 'Ural') phylogroups. The host and its parasite are common and geographically widespread in all over the western Palearctic region except in the Mediterranean biome (Spitzenberger 1999).

Comparative phylogeographical approaches have also been developed in several studies (Wickström et al. 2003; Nieberding et al. 2005; Biek et al. 2006; Whiteman et al. 2007). Parasites have notably been used to resolve the evolutionary and ecological history of their host (Nieberding and Olivieri 2007). It have been found to have often more structured populations than their host, suggesting lower rates of gene flow, but the reverse has also been found in some species (McCoy et al. 2005). The extent to which the spatial structure of parasite populations mirrors patterns seen in host populations seems to depend on the degree to which they are dependent on the host (Barrett et al. 2008). Indeed, host vagility should be a major determinant of parasite gene flow because many parasites have no free-living stages or have low dispersal capability in their free-living stages (McCoy et al. 2003; Criscione et al. 2005). Consequently, gene flow in a parasite with multiple host species will be controlled by the more mobile host (Criscione et al. 2005). Divergent patterns between host and parasite may imply that additional host species play a role in dispersing the parasite (Jones and Britten 2010). However, the links between the host specificity of a parasite and a congruent signal between their phylogeographic patterns are still poorly studied.

Mitochondrial DNA was used for phylogeographic studies. It is a molecule that has specific characteristics different from those of the nuclear DNA, which made it very attractive for the researchers (Ballard and Whitlock 2004). Characteristics as its abundance, its simple genetic structure (haploid) due to its uniparental transmission (maternal inheritance generally), its small size and the absence of introns and recombination facilitate its amplification and its sequencing. The arrangement of its genes was very stable between various taxonomic classes. However, phylogeographic studies using genetic marker such as the gene coding for the cytochrome $b$ of the mitochondrial DNA (mtDNA) have been developed in order to examine the phylogeographic patterns of vertebrate and invertebrate taxa. For this purpose, we studied the phylogeographical structure of the nematode parasite (Heligmosomum mixtum) (Heligmosomidae) and we compared it to those of its most commonly host, the bank vole (Myodes glareolus). However, this nematode seems to have also the ability to infect other rodent hosts such as Clethrionomys rutilus, the vole Microtus arvalis, Microtus agrestis and Microtus socialis and the gerbill Meriones persicus (Haukisalmi et al. 1996; Mezeika et al. 2003; Grikieniennë 2005; Kia et al. 2010; Zhigileva 2011). In contrast to its related species, the nematode Heligmosomoides polygyrus, which is characterized by an important congruent phylogeographic pattern as compared to its specific host, the wood mouse (Apodemus sylvaticus), we therefore hypothesize that $H$. mixtum would be characterized by a weaker phylogeographic structure, which would be divergent to those of its major host, the bank vole. In this scope, the aims of the present study are: (i) to verify, by sequencing the mitochondrial DNA cytochrome b gene (cyt b), the hypothesis of a weak congruence between the phylogeographic structure of H. mixtum and M. glareolus; and (ii) to discuss the particularities of H. mixtum phylogeographical pattern as compared with those of other invertebrate taxa, in the light of the knowledge on the population genetic structure and the genetic diversity of nematode parasite species.

\section{Materials and Methods}

\section{Sample collection and sequencing}

A set of 119 adult Heligmosomum mixtum from 10 localities in Europe were analyzed (Table I, Fig. 1). All samples were identified at the species level. Tissues are held in the collection of Michaux J., Nieberding C., Deffontaine V., Libois R., Henttonen H., Niemima J.

DNA from H. mixtum was extracted as reported by Goüy de Bellocq et al. (2001). A total of $591 \mathrm{bp}$ for the cyt b gene were amplified by the polymerase chain reaction (PCR). Specific primers are used 3F (5'-CTGCTGATGGYTCAA TAGCTT-3') and 3R (5'-GGGTCACCCAACCTAAAAGG3'. These primers were defined using Primer3 software (version 4.0.0) (Koressaar and Remm 2007). Amplifications were carried out in $50 \mu \mathrm{L}$ volumes including $0.35 \mu \mathrm{L}$ of each 100 $\mu \mathrm{M}$ primer, $4 \mu \mathrm{L}$ of $1 \mathrm{mM}$ dNTP, $10 \mu \mathrm{L}$ of 5 Xreaction buffer, $29 \mu \mathrm{L}$ of purified water, $4 \mu \mathrm{L}$ DMSO and $0.5 \mu \mathrm{L}$ of $5 \mathrm{U} / \mu \mathrm{L}$ Go TAQ DNA polymerase. PCR amplification used $2 \mu \mathrm{L}$ of DNA extract. Amplifications were performed at $94^{\circ} \mathrm{C}$ for $4 \mathrm{~min}$, followed by 40 cycles $\left(45 \mathrm{~s}\right.$ at $94^{\circ} \mathrm{C}, 45 \mathrm{~s}$ at $54^{\circ} \mathrm{C}$ and $1 \min 30$ $\mathrm{s}$ at $72^{\circ} \mathrm{C}$ ) with final extension cycle of $10 \mathrm{~min}$ at $72^{\circ} \mathrm{C}$ with a Labover PTC100 Thermal Cycler. PCR products were purified using the Ultrafree DA Amicon kit and directly sequenced. Both strands were sequenced by Macrogen Society (Seoul, South Korea). 


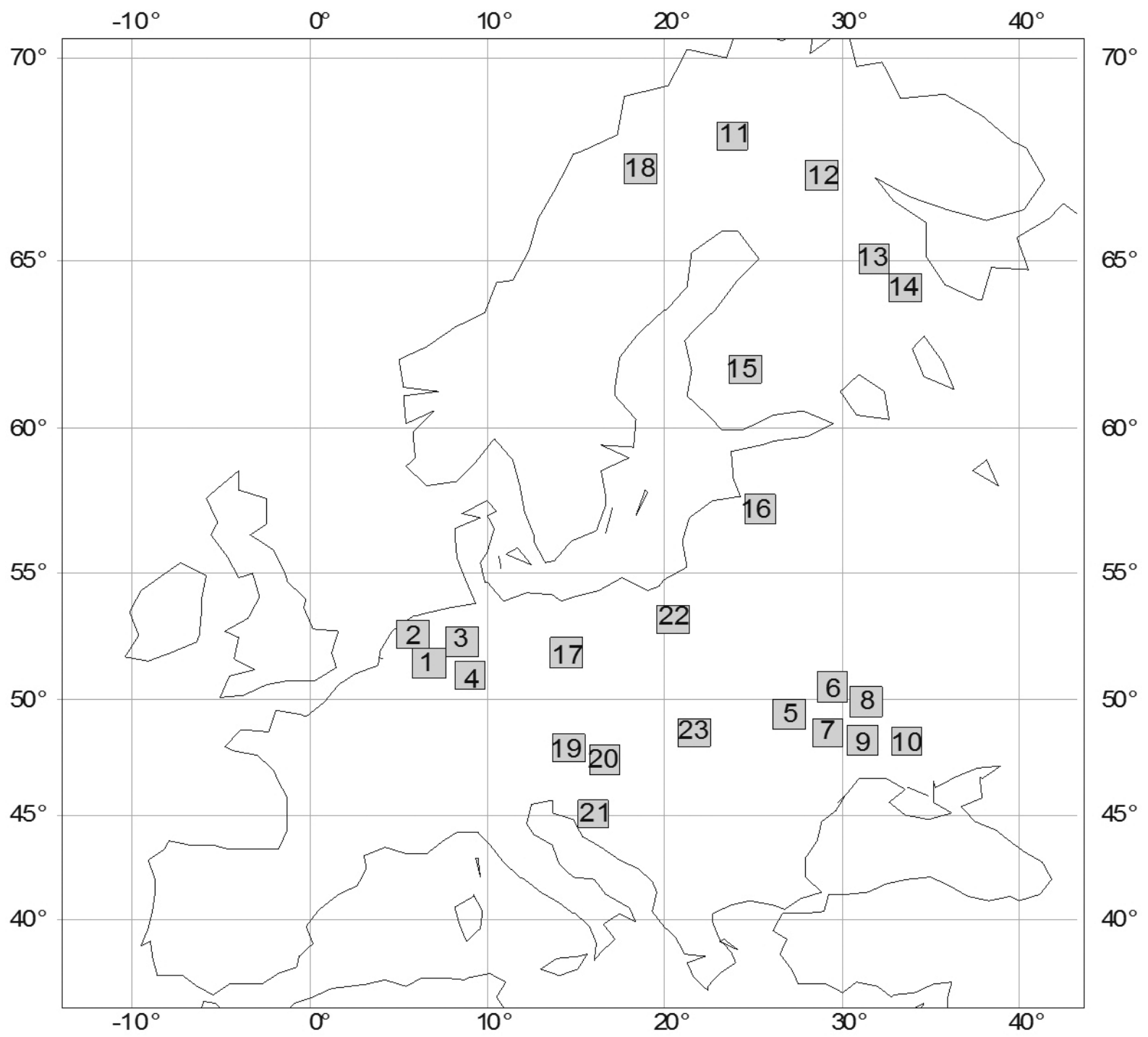

Fig. 1. Geographic distribution of H. mixtum in the Palearctic region: $\mathbf{1}$ - Virelles; $\mathbf{2}$ - Colonster; $\mathbf{3}$ - Marcourt; 4 - Havelanj; 5 - Transylvanie Tirgu; 6 - Transylvanie Zarnesti; 7 - Crisana Ineu; 8 - Banat Baile; 9 - Brasov; 10 - Timisoara; 11 - Pallasjärvi; 12 - Sodankyla; 13 - Transect, Rautjärvi; 14 - Transect, Joutseno; 15 - Finland South; 16 - Lithuania; 17 - Germany; 18 - Sweden 19 - Austria Ginzling; 20 - Austria Tirol ventetal; 21 - Croatia; 22 - Poland; 23 - Hungary

\section{Data analysis}

Sequences of haplotypes were submitted to NCBI GenBank (Table I) (Accessions numbers: HG966618 to HG966671 for the 54 haplotypes of H. mixtum).

The sequences were aligned using the ClustalW package in the BIOEDIT program, version 7.0.0 (Hall 1999) and analyzed with MEGA program version 5 (Tamura et al. 2011). Aligned sequences were analyzed with DnaSP software version 5.10.01 (Librado and Rozas 2009) to estimate polymorphisms indices. Indices of haplotypes diversity (Hd) (Nei and Tajima 1983) and pairwise estimates of nucleotide diversity (Pi) (Jukes and Cantor 1969) were used to appreciate genetic diversity among the studied populations. The mean of genetic diversity was calculated for each population and for overall $\mathrm{H}$. mixtum animals.

\section{Phylogenetic reconstruction}

The alignment was manually checked and pairwise sequence divergence between individuals of $H$. mixtum was calculated according to the Maximum Composite Likelihood (MCL) (Tamura et al. 2004). Phylogeny reconstruction was performed using Neighbor-Joining (NJ) (Saitou and Nei 1987), Maximum parsimony (MP) methods applying MEGA Version 5 software (Tamura et al. 2011) and Maximum Likelihood approaches, with the PHYML package (ML) (Guindon and Gascuel 2003). PHYML trees were constructed with 1000 bootstrap replicates. Phylogenetic trees were rooted with cyt $\mathrm{b}$ sequences from two Heligmosomoides polygyrus, a related species. The Akaike Information Criterion in Model test version 3.06 (Posada and 
Table I. Geographical locations, sample abbreviations and Genbank accession numbers of H. mixtum haplotypes used in this study

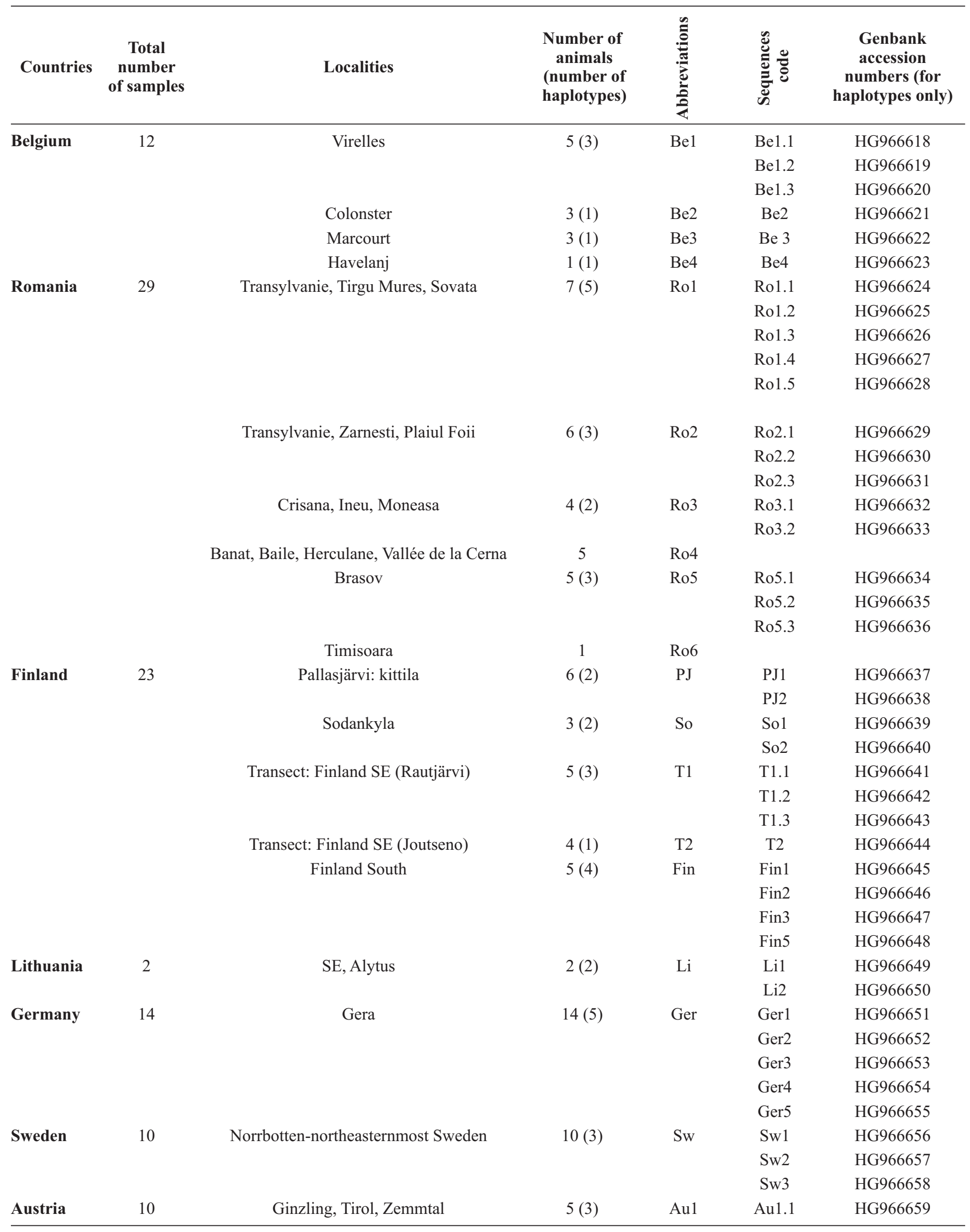




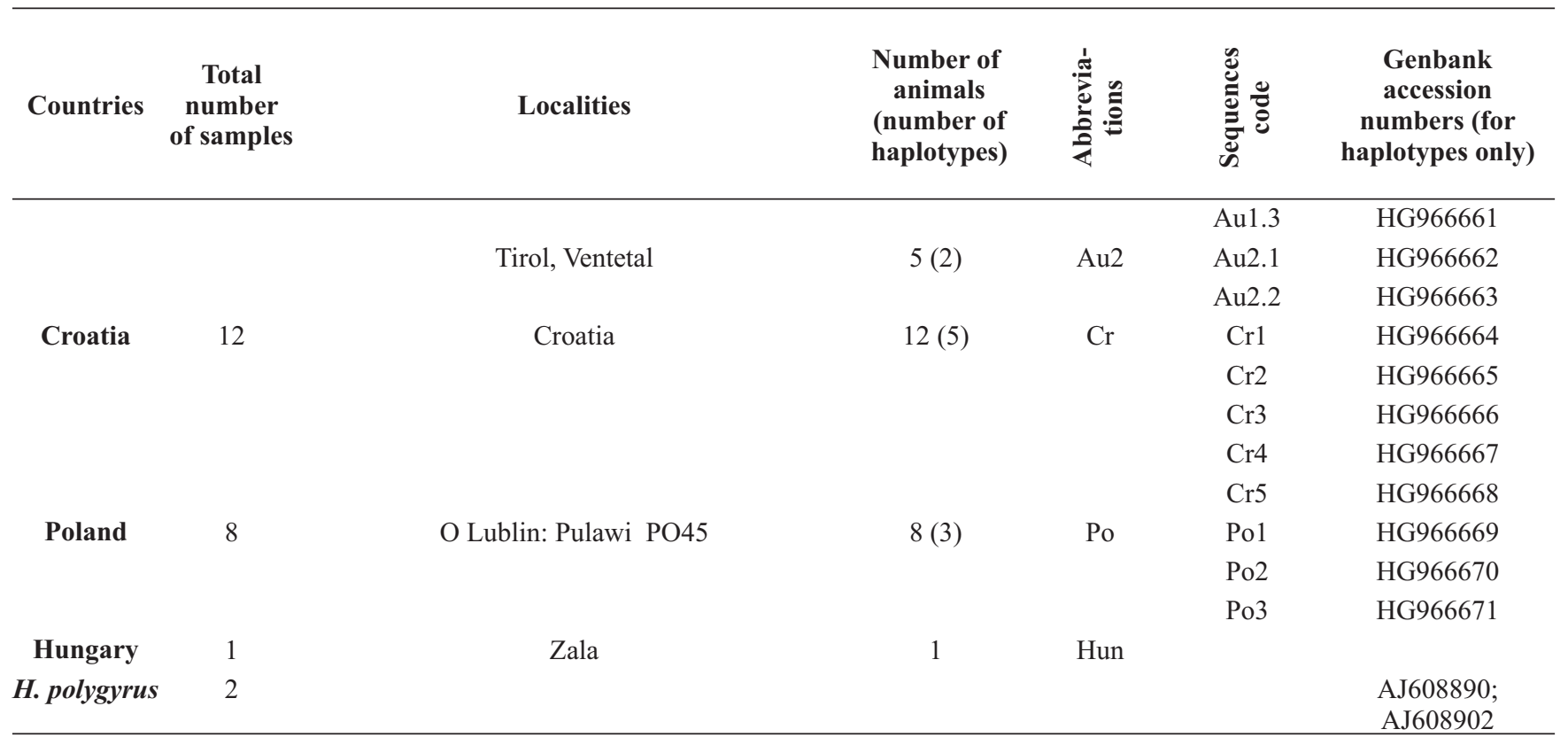

Crandall 1998) was used to select the best substitution model for the parasite data in the ML reconstructions which was GTR plus gamma.

The genetic relationship of the haplotypes was also graphically displayed using the algorithm MINSPNET available in the program Arlequin 3.5 (Excoffier et al. 2005). The Minimum Spanning Network (MSN) computes a Minimum Spanning Tree (MST) and Network (MSN) among haplotypes. $\mathrm{F}_{\mathrm{st}}$ (Hudson et al. 1992), $\mathrm{G}_{\mathrm{st}}$ (Nei 1973) and $\mathrm{N}_{\mathrm{st}}$ (Lynch and Crease 1990) were analyzed with DnaSP, version 5.10.01 (Librado and Rozas 2009). $\mathrm{F}_{\text {st }}$ index is widely used to estimate the degree of subdivision between populations and $\mathrm{G}_{\mathrm{st}}$ depends only on the frequencies of the haplotypes. $\mathrm{N}_{s t}$ is influenced by both haplotype frequencies and genetic distances between haplotypes. Moreover, the strengths of gene flow $\left(\mathrm{N}_{\mathrm{m}}\right)$ and random drift were accessed from $\mathrm{F}_{\mathrm{st}}, \mathrm{G}_{s t}$ and $\mathrm{N}_{\mathrm{st}}$ parameters.

\section{Phylogeographical and genetic structure analyses}

Selection neutrality for the detected mutations was tested by both Tajima's D (Tajima 1989) and Fu and Li's D* and F* methods (Fu and Li 1993). Demographic parameters were assessed using the distribution of pairwise sequence differences (mismatch distribution) of Rogers and Harpending (1992) and site-frequency spectra (distribution of the allelic frequency at a site) of Tajima (1989) using the program DnaSP software version 5.10.01 (Librado and Rozas 2009). This analysis provided an estimate of the population dynamics either in recent expansion or rather stable in time in the different lineages. The smoothness of the observed distribution was quantified by the raggedness statistic, $r$ (Harpending 1994) and Ramos-Onsins statistic, R2 (Ramos-Onsins et al. 2002). The confidence intervals were provided by computer simulations using the coalescent algorithm in DnaSP software. This powerful pop- ulation expansion test takes into account haplotype frequencies under neutrality, stationarity and panmixis, as described by Ewens (1972), but is sensitive to background selection. Fu's Fs test (Fu and Li 1993) was used to access historical changes in population size. Fu's Fs is sensitive to demographic expansion and can be used to estimate exponential population growth or decline (Lessa et al. 2003).

On the basis of the percentage of genetic divergence (GD) obtained with a distance analysis (K2P distance), and was corrected for ancestral mtDNA polymorphism, as proposed by Avise (2000) using the formula: $\mathrm{P}_{\text {net }}=\mathrm{P}_{\mathrm{AB}}-0.5\left(\mathrm{P}_{\mathrm{A}}+\mathrm{P}_{\mathrm{B}}\right)$. Where $\mathrm{P}_{\text {net }}$ is the corrected distance between the isolated lineages $A$ and $\mathrm{B}, \mathrm{P}_{\mathrm{AB}}$ is the mean genetic distance in pairwise comparisons of individuals A vs. $\mathrm{B}$, and $\mathrm{P}_{\mathrm{A}}$ and $\mathrm{P}_{\mathrm{B}}$ are mean genetic distance among individuals within these lineages. However, it is generally problematic to calibrate the absolute rate of evolution of invertebrate parasites because of lacking fossil records.

\section{Results}

\section{Sequence variation in the cytochrome b gene}

The length of the cytb mt DNA ranged from $511 \mathrm{bp}$ to $591 \mathrm{bp}$ with an average of $596 \mathrm{bp}$ among the 119 sequences of $H$. mixtum analysed. The average GC contents of the cytb mt DNA was $28.9 \%$. The transition/transversion rate ratios were: $\mathrm{K} 1=$ 21.104 (purines) and $\mathrm{K} 2=10.067$ (pyrimidines). The overall transition/transversion bias (R) was 5.773. This result shows that the transitions are more frequent than transversions at the cytb mtDNA (Table II). The different substitutions detected are given in table II and shows that the $\mathrm{A} \rightarrow \mathrm{G}$ and $\mathrm{T} \rightarrow \mathrm{C}$ transitions are more frequent than $\mathrm{G} \rightarrow \mathrm{A}$ and $\mathrm{C} \rightarrow \mathrm{T}$ transitions in the $c y t \mathrm{~b}$ gene. 
Table II. Maximum Composite Likelihood Estimate of the Pattern of Nucleotide Substitution in cytochrome b gene

\begin{tabular}{cccccc}
\hline & A & T & C & G \\
\hline A & - & 2.78 & 0.45 & $\mathbf{2 6 . 1 7}$ \\
T & 1.4 & - & $\mathbf{4 . 5 4}$ & 1.24 \\
C & 1.4 & $\mathbf{2 8}$ & - & 1.24 \\
G & $\mathbf{2 9 . 5 5}$ & 2.78 & 0.45 & - \\
\hline
\end{tabular}

Rates of different transitional substitutions are shown in bold and those of transversionsal substitutions are shown in italics. Evolutionary analyses were conducted in MEGA5 (Tamura et al. 2011)

Table III. Summary of genetic polymorphisms observed in H. mixtum animals used in this study

\begin{tabular}{lc}
\hline \multicolumn{1}{c}{$\boldsymbol{H}$. mixtum } & All individuals \\
\hline Number of sequences & 119 \\
Alignment length (bp) & 487 \\
Monomorphic characters & 422 \\
Variable characters & 65 \\
Parsimony informative characters & 36 \\
Singleton variable sites & 29 \\
Total number of mutations & 66 \\
Number of polymorphic sites (S) & 65 \\
Number of haplotypes (H) & 54 \\
Haplotype diversity (Hd) \pm SD & $0.968 \pm 0.007$ \\
Variance of haplotype diversity & 0.00004 \\
Nucleotide diversity (Pi) \pm SD & $0.00851 \pm 0.00048$ \\
Theta (per site) from Eta & 0.02532 \\
Average of pairwise differences (K) & 4.144 \\
Minimum number of recombination events (Rm) & 8 \\
\%GD genetic diversity (K2P) & 0.009 \\
Tajima's D & -2.10850 \\
Fu and Li's D* & $(* \mathrm{P}<0.05)$ \\
Fu and Li's F* & -3.30214 \\
Fu's Fs statistic & $(* * \mathrm{P}<0.02)$ \\
\hline
\end{tabular}

SD: Standard deviation, Tajima's D, Fu and Li's D* and Fu and Li's F*: neutrality tests

Table IV. Genetic variability and mean genetic diversity observed within the different populations of Heligmosomum mixtum

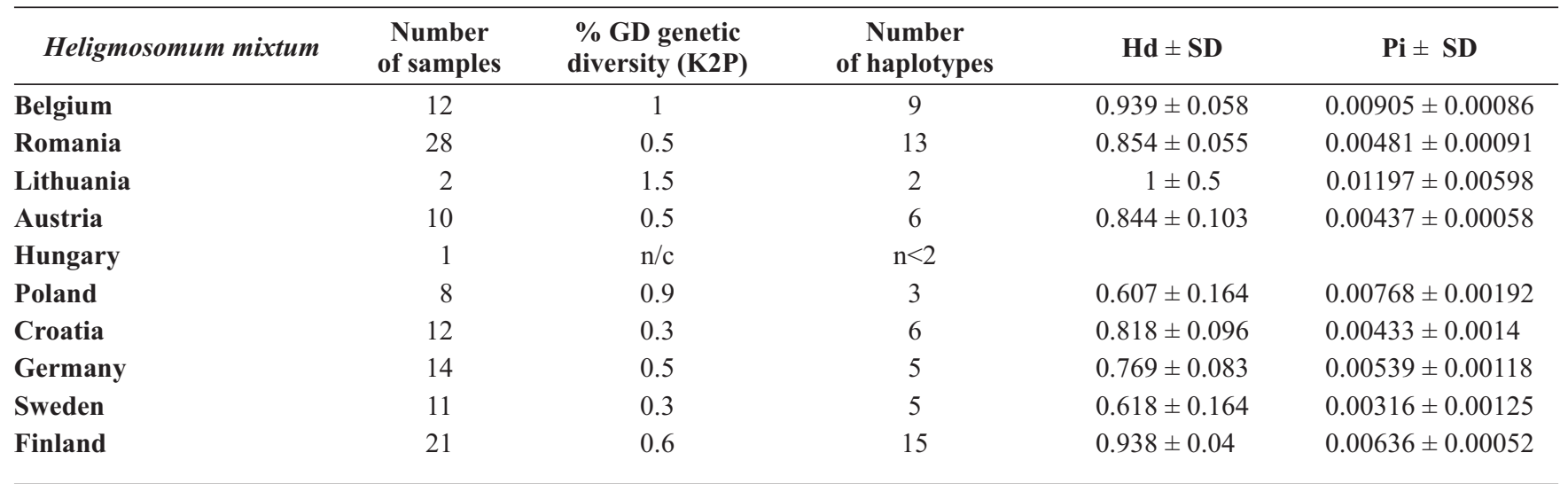


Sequence alignment resulted in a matrix of 591 bp characters. Of the 65 variable sites, 36 were parsimony-informative and 29 were singleton variable sites (Table II). The nucleotide frequencies were $23.84 \%, 47.36 \%, 21.12 \%$ and $7.6 \%$ for $\mathrm{A}, \mathrm{T}, \mathrm{C}$ and $\mathrm{G}$ respectively.

\section{Genetic variability and differentiation}

The Aligned Sequences allowed identifying 54 mtDNA haplotypes among 119 individuals examined. Within the whole dataset, the haplotype diversity (Hd) was estimated to 0.968 and the nucleotide diversity (pi) to 0.00851 (Table III). The mean of genetic diversity was estimated to $0.9 \%$ for the studied H. mixtum animals (Table III). The Théta (per site) from Eta and the average number of pairwise differences (K) are $0.02532,4.144$ respectively for overall data set (Table III).

The recombination rate is also an important parameter affecting patterns of DNA polymorphism. In H. mixtum, 8 recombination events were detected at whole data sequences. Sites touched by recombination events were $(99,243)$; (267,285); (285,303); (324,327); (390,396); (396,417); $(438,447)$ and $(447,477)$. Value of Rm per informative sites was 0.222 for the overall data set sequences (Table III).

The nucleotide diversity was calculated for each population of H. mixtum. The results of these analyses are summarized in table IV and indicate that the Belgium and Poland animals have the highest level of nucleotide diversity 0.00905 and 0.00768 , respectively. Moreover, the Finnish animals showed a relatively high level of nucleotide diversity (0.00636). The other populations have an intermediate value of nucleotide diversity. Animals from Lithuania showed a high value of nucleotide diversity. However, this result must be taken with caution because the sampling for this region was very low $(\mathrm{N}=2)$ (Table IV).

The genetic variability registered between the populations of $H$. mixtum was low and ranged from 0.3 to $1.5 \%$ (maximum $1.5 \% \mathrm{~K} 2 \mathrm{P}$ genetic diversity is observed in Lithuania animals). However, these data must be interpreted with caution because the sampling for this region was very low $(\mathrm{N}=2)$. Populations of H. mixtum from Belgium and Poland showed a relatively high level of genetic diversity, $1 \%$ and $0.9 \%$ respectively (Table IV). The K2P genetic distances observed among the animals from the different regions were high (between 0.2 to $1.7 \%$ of $\mathrm{K} 2 \mathrm{P}$ distance; Table $\mathrm{V}$ ). $\mathrm{F}_{\mathrm{st}}, \mathrm{G}_{\mathrm{st}}$ and $\mathrm{N}_{\mathrm{st}}$ parameters were estimated. $\mathrm{G}_{\mathrm{st}}$ was calculated based on haplotype frequencies, whereas $\mathrm{N}_{\mathrm{st}}$ takes into account the genetic relation among haplotypes. The level of differentiation in allele frequencies between groups was measured by $\mathrm{F}_{\mathrm{st}}$ (Wright 1951). When $\mathrm{N}_{\mathrm{st}}$ value is higher than the $\mathrm{G}_{\mathrm{st}}$ estimated, it indicates the presence of a phylogeographical structure as noted by Petit et al. (2005). The $F_{\text {st }}$ values in the range of $0.07-0.59$ were registered between the different populations of $H$. mixtum. The highest value of $\mathrm{F}_{\mathrm{st}}(0.59)$ is registered between populations from Croatia and Sweden. Parasites from Lithuania 


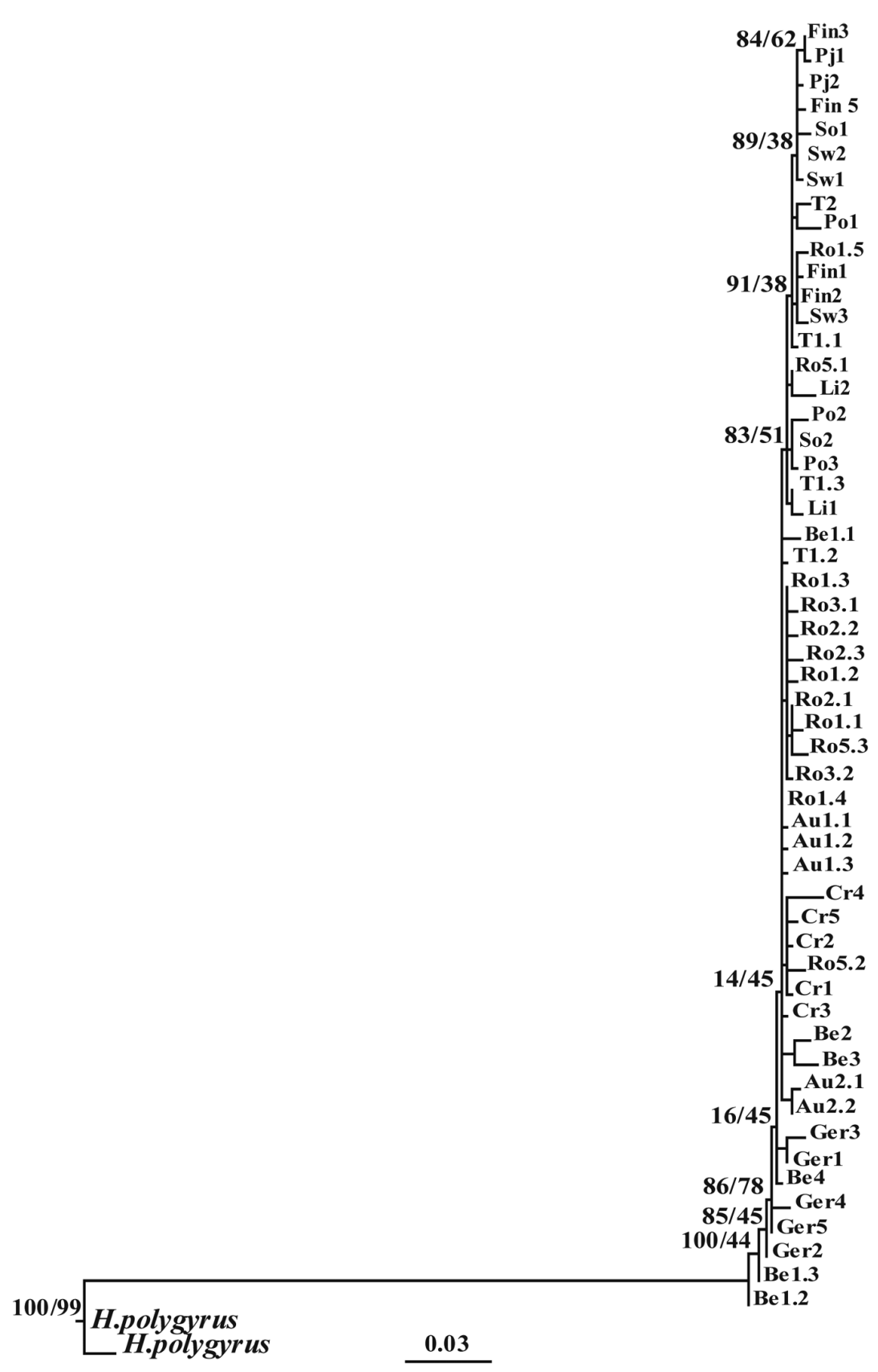

Fig. 2. Most likely tree of the PHYML reconstruction for the $54 \mathrm{mt}$ DNA haplotypes of Heligmosomum mixtum and the two Heligmosomoides polygyrus outgroups. Numbers on branches indicate, from left to right (a) bootstrap support in the PHYML analysis, (b) bootstrap support obtained in the $\mathrm{NJ}$ reconstruction

and Poland have a low value of $\mathrm{F}_{\text {st }}(0.08)$ suggesting a frequent gene flow between these regions. However, $F_{\mathrm{st}}$ is also low between the Finnish animals and those from Sweden (0.07) suggesting recent contacts between these regions (Table VI).

The estimated $\mathrm{F}_{\mathrm{st}}(0.365)$ and $\mathrm{G}_{\mathrm{st}}(0.175)$ are low and agree with assumption that a balancing selection activates at the cytb mtDNA. Here, the $\mathrm{N}_{\mathrm{st}}(0.366)$ and the $\mathrm{G}_{\mathrm{st}}(0.175)(\mathrm{P}<0.05)$ suggested the presence of gene flow between the different populations of $H$. mixtum as demonstrated by values of $\mathrm{N}_{\mathrm{m}}$ $\left(0.43 ; 1.17\right.$ and 0.43 estimated on the basis of $\mathrm{F}_{\mathrm{st}}, \mathrm{G}_{\mathrm{st}}$ and $\mathrm{N}_{\mathrm{st}}$ indices, respectively).

\section{Genetic relationships based on cytochrome b}

Phylogenetic trees were reconstructed using Maximum Parsimony (MP), ML and neighbor-joining (NJ) methods. Parsimony analysis showed a low homoplasy. Indeed, the consistency index $(\mathrm{CI})$, the retention index (RI) and the homplasy index (HI) were 0.7364 , of 0.7434 and 0.2566 , respectively. The Maximum 
Table VI. Genetic differentiation ( $\mathrm{F}_{\text {st }}$ values) between the studied populations of Heligmosomum mixtum

\begin{tabular}{|c|c|c|c|c|c|c|c|c|c|}
\hline H. mixtum & Belgium & Romania & Lithuania & Austria & Poland & Croatia & Germany & Sweden & Finland \\
\hline \multicolumn{10}{|l|}{ Belgium } \\
\hline Romania & 0.27956 & & & & & & & & \\
\hline Lituania & 0.16898 & 0.18981 & & & & & & & \\
\hline Austria & 0.25613 & 0.39139 & 0.11111 & & & & & & \\
\hline Poland & 0.42483 & 0.50611 & 0.33049 & 0.47913 & & & & & \\
\hline Croatia & 0.31074 & 0.44707 & 0.08442 & 0.40783 & 0.55694 & & & & \\
\hline Germany & 0.28303 & 0.41351 & 0.19741 & 0.28790 & 0.43574 & 0.45320 & & & \\
\hline Sweden & 0.41209 & 0.52410 & 0.30376 & 0.52823 & 0.53416 & 0.59753 & 0.55248 & & \\
\hline Finland & 0.26256 & 0.34902 & 0.13418 & 0.32218 & 0.42130 & 0.39158 & 0.36957 & 0.07121 & \\
\hline
\end{tabular}

Likelihood (ML) tree is illustrated in Fig. 2. This tree shows a huge polytomy among the studied animals and suggests the existence of a great genetic homogeneity within this dataset. The topology of ML tree is made independently of the geographic origin of parasites. Indeed, the NJ tree showed similar topology than obtained by ML. The bootstrap values of this last analysis were added to the ML tree (Fig. 2).

\section{Demographic analysis}

We employed different statistical methods to determine if the patterns of diversity observed in $H$. mixtum species in the $c y$ tochrome $\mathrm{b}$ of mtDNA deviated significantly from an equilibrium neutral model. Selective neutrality tests show that Tajima's as well and Fu and Li's tests were negative and significant for the animals studied (Table III). The observed variation patterns provide evidence that $H$. mixtum have been undergoing rapid expansion. The Fu's Fs statistic results demonstrate that the genetic effect of hitchhiking was ruled out by Fu's test. The calculated values were highly negative and significant (Fu's Fs $=-52.426 ; \mathrm{P}=0.000$ for the all data set sequences) (Table III and Fig. 3a). This result confirms a signal of population expansion of $H$. mixtum and positive selection without a hitchhiking effect (negative D-value) as described by Eswaran et al. (2005). This was also supported by significant values of $\mathrm{Fu}$ and Li's statistical tests ( $\mathrm{F}^{*}:-3.30214$; $\left.{ }^{* *} \mathrm{P}<0.02 ; \mathrm{D} *:-3.35691 ;{ }^{* *} \mathrm{P}<0.02\right)$ for all data set sequences. A signature of population growth (unimodal pattern) was also clearly evident in the distribution of pairwise nucleotide distribution within the total animals $(n=119)$ (Fig. 3b). These results are corroborated by Harpending's raggedness index and Ramos-Onsins statistic $(r=0.08921, \mathrm{R} 2=0.16021)$ in H. mixtum cytb DNA sequences.

\section{Haplotype distribution}

To improve the genealogical relationships assessment between haplotypes in H. mixtum, a minimum spanning network was
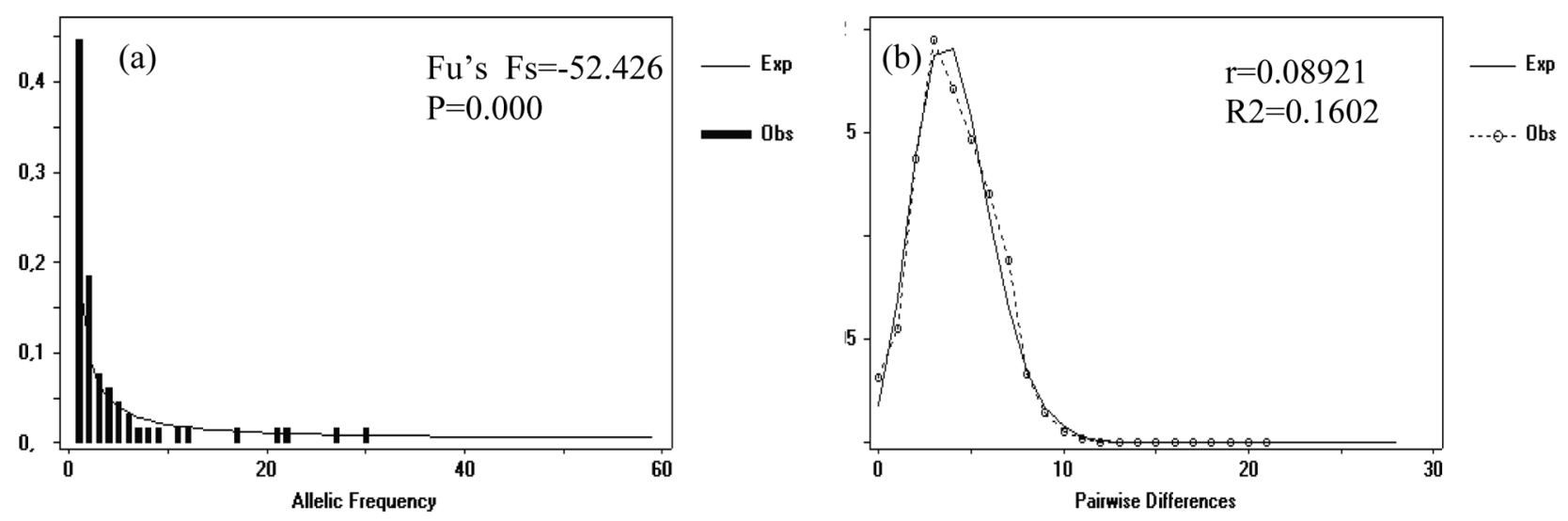

Fig. 3. Site frequency spectra and mismatch distribution of the cytochrome b sequences of $H$. mixtum based on pairwise nucleotide differences in the overall data set sequences. (a) Solid lines in the site-frequency spectra indicate the expected distributions under neutrality and at equilibrium. Fu's Fs statistics and corresponding P- values are given; (b) Solid lines in the curves indicate the expected distribution under expansion and dotted lines indicate the observed distribution under population expansion. The ranggedness and Ramos-Onsins and Rozas statistics, corresponding $\mathrm{r}$ and $\mathrm{R} 2$ statistic values are given. 


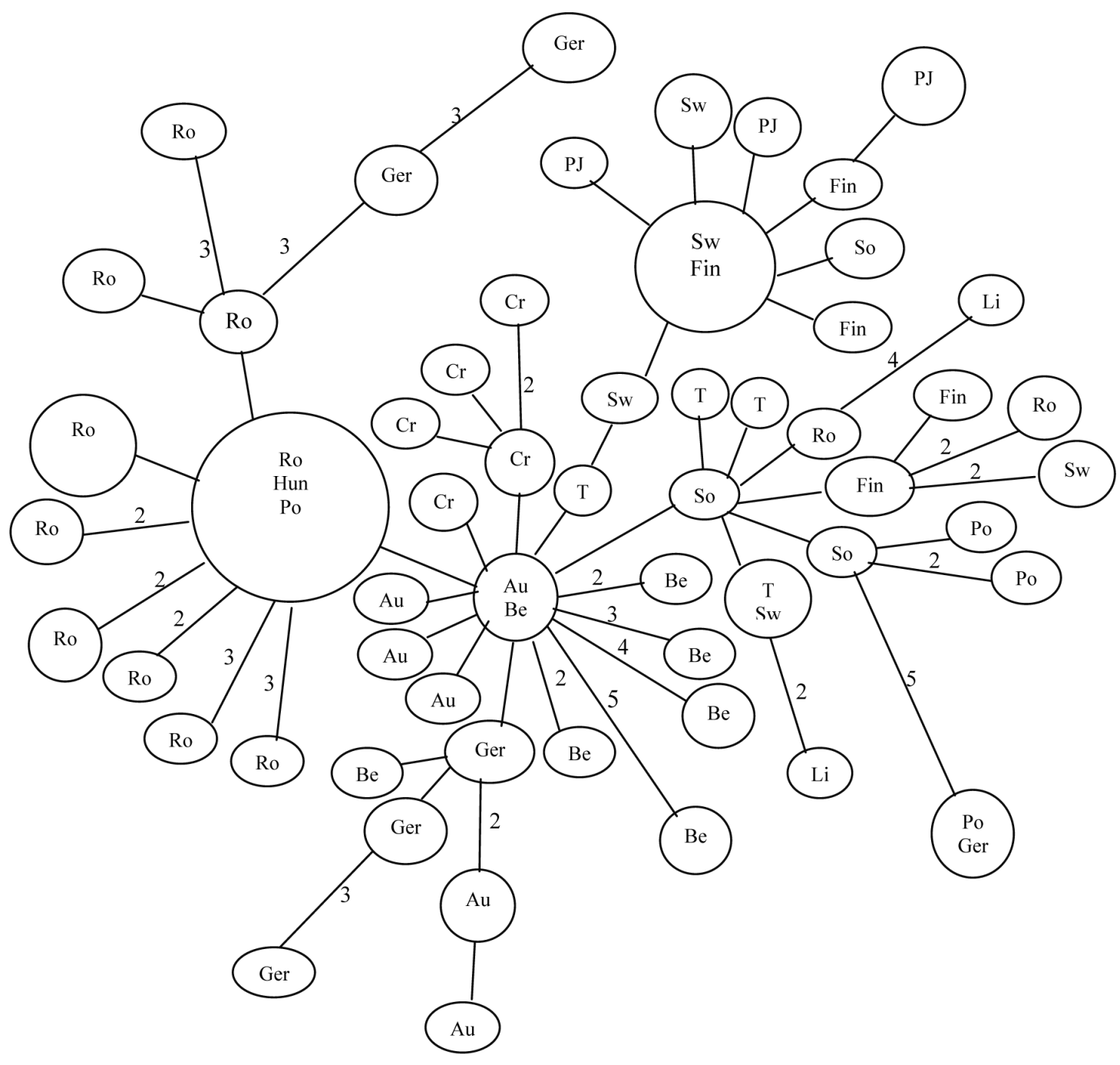

Fig. 4. Minimum spanning network constructed using mitochondrial cytochrome b gene sequences. Numbers correspond to the mutational steps observed between the inferred haplotypes of H. mixtum: Ro - Romania; Cr - Croatia; Be - Belgium; So - Sodankyla; Ger - Germany, Au - Austria T - Transect; Hun - Hungary; Po - Poland; Li - Lithuania; Fin - Finland, PJ - Pallas jarvi, Su - Sweden

constructed by linking sequences in a hierarchical manner based on mutational changes between them. Fig. 4 shows the genetic network of the detected haplotypes using the cytb mt DNA. Because most genetic variants arose recently, the haplotype patterns should reflect a signature of relative recent expansion of $H$. mixtum. Indeed, populations of $H$. mixtum are linked to three main haplotypes. The first one is composed of animals from Romania, Hungary and Poland; the second one is represented by Sweden and Finnish animals and finally the third one is composed of animals from Belgium and Austria which display the highest number of connections (Fig. 4). The other individuals are dispersed among the described haplotypes. The number of mutational steps which separated haplotypes ranged from one to five suggesting close relationships between the inferred haplotypes. Fig. 4 revealed the same result as the phylogenetic tree. Indeed, the distribution of haplotypes showed a star-like topology without any geographic structure.

\section{Discussion}

\section{Genetic variability in cytochrome b for $\boldsymbol{H}$. mixtum}

The mean length of the cyt b mtDNA in H. mixtum is $596 \mathrm{bp}$ and the nucleotide frequencies are $23.84 \%, 47.36 \%, 21.12 \%$ and $7.6 \%$ for $\mathrm{A}, \mathrm{T}, \mathrm{C}$ and $\mathrm{G}$ respectively. Similar results have been reported in $H$. polygyrus (687 bp), specific parasite of A. sylvaticus, where the base composition was $25.68 \%, 48.97 \%$ $5.73 \%$ and $19.62 \%$ for A, T, C and G, respectively (Nieberding et al. 2005). The level of transition/transversion which registered in H. Mixtum (5.773) was higher than those observed in H. polygyrus ( $\mathrm{ti} / \mathrm{tv}=2.18)$ (Nieberding et al. 2005).

The mean cytochrome b level of genetic diversity of $\mathrm{He}$ ligmosomum mixtum ( $0.9 \%$ in the whole data set) was low in comparison with its related species Heligmosomides polygyrus (6.7\%) (Nieberding et al. 2005). This result would be partly 
explained by abundance and prevalence of $H$. polygyrus on A. sylvaticus which is quite high, involving a rapid accumulation of mutations and ensuring the parasite genetic diversity (Nieberding et al. 2005). The level of genetic diversity observed in $H$. mixtum also appears very low as compared to other invertebrate taxa like the cestode Paranoplocephala arctica paraziting collared lemmings (4.5\%) (Wickström et al. 2003 ) and other species like the snails Biomphalaria glabrata $(5.9 \%)$; the insects (e.g. Maoricicada campbelli $(2 \%)$; Peltoperla tarteri (4\%); Tarphius canariensis (5.8\%)) (Emerson et al. 2000; Buckley et al. 2001; Trewick and Wallis 2001; Mavarez et al. 2002; Schulthesis et al. 2002). The nucleotide and haplotype diversities observed in H. mixtum appear also very low as compared to the values observed in other parasite or invertebrate species. Such results could be explained by three scenarios:

- (1) A historical one: the parasite may have undergone frequent bottlenecks during the quaternary glaciations which may have induced a reduction of the genetic diversity of this parasite.

- (2) The eradication of the diversity within populations of the parasite may also be related to its biology and the reproductive cycle. Indeed, cold conditions may affect the living cycle of $H$. mixtum and the development of the free-living larval stages to infective L3s is almost certainly slowed and or suspended during cold winter (Haukisalmi et al. 1988).

- (3) The low genetic variation in H. mixtum is explained by the fact that $H$. mixtum is a host generalist. It seems that host specialist parasites have more genetic structure.

\section{Lack of phylogeographic structure in $\mathrm{H}$. mixtum}

The different phylogenetic trees constructed with the inferred haplotypes evidenced a great genetic homogeneity among the studied H. mixtum (Fig. 2) as compared to the complex phylogeographic structure of its main host, the bank vole (M. glareolus) (see Deffontaine et al. 2005, 2009). This strong incongruence between the host and parasite phylogeographic patterns could be explained by the ability of $H$. mixtum to switch on different other host species like the fieldmouse Apodemus flavicollis, the vole Microtus arvalis and Microtus socialis and even the gerbill Meriones persicus (Mezeika et al. 2003; Grikieniennë 2005; Kia et al. 2010). Indeed, the high vagility of $H$. mixtum and its host generalist behavior probably influenced its degree of genetic differentiation and its phylogeographic structure. Switching on different host species, its dispersal habits could be totally different as compared to those of its main host, M. glareolus. This would have facilitated a genetic homogenisation of its populations throughout all Europe, which lead to the present weak phylogeographic structure. Similar data have been found since unstructured genetic variability have been registered using other molecular markers (Dybdahl and Lively 1996; Nieberding et al. 2008).

This host switching hypothesis was also proposed to explain some incongruences between the phylogeographic struc- ture of H. polygyrus and A. sylvaticus (Nieberding et al. 2008). Indeed, this parasite species can also switch sometimes on other Apodemus species (eg A. flavicollis, A. uralensis, etc.). This probably led to particular phylogeographic patterns observed in some regions for the parasite, as compared to the one of its host (Nieberding et al. 2008).

The same signal of a weak geographic structure was also observed on the cestode Paranoplocephala artica. For this latter species, an indeterminate intermediate host might be responsible of such pattern (Wickström et al. 2003). Another example concerns the snail Potamopyrgus antipodarum, which forms a collection of highly structured populations; whereas its trematode parasite Microphallus exhibits weak population structure because of the dispersal abilities of its final bird host species (Dybdahl and Lively 1996).

Our results and these last examples tend to confirm that the phylogeographic congruence between parasites and their host should be rather rare and that this phenomenon would be only observed when there is a high specificity between the parasite and its host (e.g. Nadler and Hafner 1990; Mulvey et al. 1991; Parker and Spoerke 1998).

In contrast, when some particular conditions exist, like a (i) strong host-parasite specificity, (ii) a direct cycle of the parasite, (iii) a short survival time of larvae during the free stage, and (iv) a limited dispersal abilities of the parasites on their own, consequently the genetic structure of the parasite could be higher. This was particularly illustrated on the nematode Heligmosomoides polygyrus (Heligmosomoidea) which was more strongly structured than its host (Apodemus sylvaticus). This result suggests lower rates of gene flow, the parasite playing the role of a biological "evolutionary print" (Nieberding et al. 2004, 2005).

\section{Population expansion}

Population size changes give particular footprints that may eventually be detected in DNA sequence data (Tajima 1989; Slatkin and Hudson 1991; Rogers and Harpending 1992). The haplotypic relationships portrayed in the network (Fig. 4) showed clear the structuring independently of geographical origin, and the presence of a star-like topology, which suggest a recent population expansion of $H$. mixtum. Further expansion was provided by the smooth mismatch distributions of mtDNA haplotypes observed in the whole sampled animals. Simulations based on coalescent process provided statistical support for the smoothness of the observed distributions (as quantified by the raggedness indices). At demographic equilibrium, mismatch distribution is usually multi-modal, but unimodal in a population having passed through a recent demographic expansion (Slatkin and Hudson 1991; Rogers and Harpending 1992). Although, the mismatch distribution of $H$. mixtum is unimodal for the overall dataset suggesting that the parasite has undergone rapid population expansion. This result is corroborated by Fu's Fs statistic (Fu's Fs = $-52.426 ; \mathrm{P}=0.000$ for the all data set sequences) which con- 
firmed these inferences about the population dynamics of $H$. mixtum. Moreover, negative and significant Fs statistical values in the total sample gave strong evidence of past population expansion and the positive selection undergone the cytb of $\mathrm{mt}$ DNA (F*:-3.30214; **P $<0.02$; $\mathrm{D}^{*}:-3.35691 ;{ }^{* *} \mathrm{P}<0.02$ ) for all data set sequences.

Although it is difficult to date accurately the expansion time from mtDNA data, we may suggest that the recent expansion in H. mixtum population reported here could be facilitated by the Pleistocene or glaciation's overflow. Phylogeography studies on many mammals and plants have revealed that their genetic structure were influenced by geological and climatic events of Pleistocene, which result in population isolation or extinction, and subsequent expansion of the surviving types when environmental conditions became favourable. Pleistocene violent climatic cycles were occurring and geological evidence suggested considerable geological activity occurred in middle Pleistocene, affecting climate and hydrology of this region (Cordy 1991). Indeed, the expansion signal in H. mixtum populations would be associated to past bottlenecks associated to the last glacial maximum, which would have been followed by rapid population expansions at the beginning of the present interglacial period. The host generalist behavior of H. mixtum, would have favoured its postglacial recolonisation, switching from one rodent species to another and leading to its particular genetic patterns: weak phylogeographic structure, low level of genetic diversity and a rapid population expansion signal.

\section{Conclusion}

This study represents the first attempt to use DNA sequence data in a study of intraspecific relationships in H. mixtum. This study has shown that intraspecific variations occur in the $\mathrm{mt}$ DNA of H. mixtum parasites which indicates that there has been a recent and rapid expansion in their evolutionary history. According to Price (1980), parasites populations will tend to be more strongly structured than their hosts suggesting lower rates of gene flow (Burban and Petit 2003; Galbreath et al. 2012) and in a few cases host and parasites showed similar degrees of population structure (Nieberding et al. 2005). Our results showed that $H$. mixtum is less structured than its main host $M$. glareolus. Indeed, this nematode is not specific to one host species and can authorize host switching events between other syntopic species (Nieberding et al. 2008). The cytoplasmic diversity seems to be unstructured with any biogeographic repartition of the variability. The general conclusion emerging from the present study is that the genetic structure of H. mixtum is probably associated to weak host specificity.

Acknowledgements. This work was supported by grants from the Islamic Development Bank (Référence: FN : 24/TUN-05/PD26) and from the Tunisian 'Ministère de l'Enseignement Supérieur et de la Recherche Scientifique et de la Technologie ' (Projet LabB02). This article is dedicated to the late Professor Mohamed Marrakchi died 2 April 2008 for his help and fruitful advises.

\section{References}

Asakawa M. 1987. Genus Heligmosomoides Hall, 1916 (Heligmosomoidae: Nematoda) from the Japanese wood mice, Apodemus spp. III. The life-cycle of Heligmosomoides kurilensis kobayashii (Nadtochii, 1966) in ICR mice and preliminary experimental infection to jirds. Journal of the College of Dairying, $12,131-140$

Avise J.C. 2000. Phylogeography. The History and Formation of Species. Harvard University Press, Cambridge, MA

Ballard J.W.O., Whitlock M.C. 2004. The incomplete natural history of mitochondria. Molecular Ecology, 13, 729-744. DOI: 10. 1046/j.1365-294X.2003.02063.X

Barrett L.G., Thrall P.H., Burdon J.J., Linde C.C. 2008. Life history determines genetic structure and evolutionary potential of host-parasite interactions. Trends in Ecology and Evolution, 23, 678-685. DOI: 10.1016/j.tree.2008.06.017

Bauchau V., Chaline J. 1987. Variabilité de la troisième molaire inférieure de Clethrionomys glareolus (Arvicolidae, Rodentia) et sa signification évolutive. Mammalia, 51, 587-598

Biek R., Drummond A.J., Poss M. 2006. A virus reveals population structure and recent demographic history of its carnivore host. Science, 311, 538-541. DOI: 10.1126/science.1121360

Buckley T.R., Simon C., Chambers G.K. 2001. Phylogeography of the New Zealand cicada Maoricicada campbelli based on mitochondrial DNA sequences: ancient clades associated with Cenozoic environmental change. Evolution, 55, 1395-1407. DOI: 10.1111/j.0014-3820.2001.tb00661.x

Burban C., Petit R.J., 2003. Phylogeography of maritime pine inferred with organelle markers having contrasted inheritance. Molecular Ecology, 12, 1487-1495. DOI: 10.1046/j.1365294X.2003.01817.x

Cordy J.M. 1991. Paleoecology of the late glacial and early postglacial of Belgium and neighbouring areas. In: The late glacial in Northwest Europe: human Adaptation and environmental Change at the End of the Pleistocene (eds Barton N, Robers AJ, Roe DA), pp.40-47. Council for British Archaeology, London

Criscione C.D., Poulin R., Blouin M.S. 2005. Molecular ecology of parasites: elucidating ecological and microevolutionary processes. Molecular Ecology, 14, 2247-2257. DOI: 10.1111/ j.1365-294X.2005.02587.x

Deffontaine V., Libois R., Kotlík P., Sommer R., Nieberding C., Paradis E., Searle J.B., Michaux J.R. 2005. Beyond the Mediterranean peninsulas: evidence of central European glacial refugia for a temperate forest mammal species, the bank vole (Clethrionomys glareolus). Molecular Ecology, 14, 17271739. DOI: 10.1111/j.1365-294X.2005.02506.X

Deffonatine V., Ledevin R., Fontaine M.C., Quéré J-P., Renaud S., Libois R., Michaux J.R. 2009. A relict bank vole lineage highlights the biogeographic history of the Pyrenean region in Europe. Molecular Ecology, 18, 2489-2502. DOI: 10.1111/ j.1365-294X.2009.04162.x

Dybdahl M.F., Lively C.M. 1996. The geography of co-evolution: comparative population structures for a snail and its nematode parasite. Evolution, 50, 2264-2275

Emerson B.C., Oromi P., Hewitt G.M. 2000. Tracking colonization and diversification of insect lineages on islands: mitochondrial DNA phylogeography of Tarphius canariensis Coleoptera: Colydidae) on the Canary Islands. Proceedings of the Royal Society of London. Series B, Biological Sciences, 267, 21992205

Eswaran V., Harpending H., Roger A.R. 2005. Genomics refutes and exclusively African origin of humans. Journal of Human Evolution, 49, 1-18. DOI: 10.1016/j.jhevol.2005. 02.006 
Ewens W.J. 1972. The sampling theory of selective neutral alleles. Theoretical Population Biology, 3, 87-112. DOI: 10.1016/ 0040-5809(72)90035-4

Excoffier L., Laval G., Schneider S. 2005. Arlequin (version 3.0): an integrated software package for population genetics data analysis. Evolutionary bioinformatics, 1, 47-50

Fu Y.X., Li W.H. 1993. Statistical tests of neutrality of mutations. Genetics, 133, 693-709

Galbreath K.E., Eric P., Hoberg E.P. 2012. Return to Beringia: parasites reveal cryptic biogeographic history of North American pikas. Proceedings of the Royal Society B, 279, 371-378. DOI: $10.1098 / \mathrm{rspb} .2011 .0482$

Goüy de Bellocq J., Ferté H., Depaquit J., Justine J.L., Tillier A., Durette-Desset M.C. 2001. Phylogeny of the Trichostrongylina (Nematoda) inferred from 28S rDNA sequences. Molecular Phylogenetics and Evolution, 19, 430-442. DOI: 10.1006/mpev. 2001.0925

Goüy de Bellocq J., Morand S., Feliu C. 2002. Patterns of parasite species richness of western Paleartic micro-mammals: island effects. Ecography, 25, 173-183

Goüy de Bellocq J., Sara M., Casanova J.C., Feliu C., Morand S. 2003. A comparaison of the strcuture of helminth communities in the woodmouse, Apodemus sylvaticus, on islands of the Western mediterranean and continental Europe. Parasitology Research, 90, 64-70. DOI: 10.1007/s00436-002-0806-1

Grikieniennë J. 2005. Investigations into endoparasites of small mammals in the environs of Lake Drûkdiai. Acta Zoologica Lituanica, 15, 109-114

Guindon S., Gascuel O. 2003. A simple, fast, and accurate algorithm to estimate large phylogenies by maximum likelihood. Systematic Biology, 52, 696-704. DOI: 10.1080/10635150390235520

Hall T.A. 1999. BioEdit: a user-friendly biological sequence alignment editor and analysis program for Windows 95/98/ NT. Nucleic Acids Symposium Series, 41, 95-98

Harpending H.C. 1994. Signature of ancient population growth in a low-resolution mitochondrial DNA mismatch distribution. Human Biology 66, 591-600

Haukisalmi V., Henttonen H., Tenora F. 1988. Population dynamics of common and rare helminths in cyclic vole populations. Journal of Animal Ecology, 57, 807-825

Haukisalmi V., Henttonen H. 1993. Populations dynamics of taenia polyacantha metacestodes in the bank vole Clethrionomys glareolus. Annales Zoologici Fennici, 30, 81-84

Haukisalmi V., Henttonen H., Vikman P. 1996. Variability of sex ratio, mating probability and egge production in an intestinal nematode in its fluctuating host population International Journal for Parasitology, 26, 755-764. DOI: 10.1016/00207519(96)00058-6

Hudson R.R., Salatkin M., Maddison W.P. 1992. Estimation of levels of gene flow from DNA sequence data. Genetics, 132, 583-590

Jones P.H., Britten H.B. 2010. The absence of concordant population genetic structure in the black-tailed prairie dog and the flea, Oropsylla hirsuta, with implications for the spread of Yersinia pestis. Molecular Ecology, 19, 2038-2049. DOI: 10.1111/j.1365294X.2010.04634.X

Jukes T.H., Cantor C.R. 1969. Evolution of protein molecules. In: Munroled, H.N. (Ed.), Mammalian Protein Metabolism. Academy Press, New York, pp. 31-132

Kia E.B., Shahryary-Rad E., Mohebali M., Mahmoudi M., Mobedi I., Zahabiun F., Zarei Z., Miahipoor A., Mowlavi Gh., Akhavan A.A., Vatandoost' H. 2010. Endoparasites of Rodents and Their Zoonotic Importance in Germi, Dashte-Mogan, Ardabil Province, Iran. Iranian Journal of Parasitology, 5, 15-20

Koressaar T., Remm M. 2007. Enhancements and modifications of primer design program Primer3 . Bioinformatics, 23, 1289 1291. DOI: 10.1093/bioinformatics/btm091
Lessa E.P., Cook J.A., Patton J.L. 2003. Genetic footprints of demographic expansion in North America, but not Amazonia, during the Late Quaternary. Proceedings of the National Academy of Sciences of the United States of America, 100, 10331-10334. DOI: 10.1073/pnas. 1730921100

Librado P., Rozas J. 2009. DnaSP v5: a software for comprehensive analysis of DNA polymorphism data. Bioinformatics, 25, 1451-1452. DOI: 10.1093/bioinformatics/btp187

Lynch M., Crease T. 1990. The analysis of population survey data on DNA sequence variation. Molecular Biology and Evolution, 7, 377-394

Mavarez J., Pointier J-P., David P., Delay B., Jarne P. 2002. Genetic differentiation, dispersal and mating system in the schistosome-transmitting freshwater snail Biomphalaria glabrata. Heredity, 89, 258-265. DOI: 10.1038/sj.hdy.6800127

Mazeika V., Paulauskas A., Balciauskas L. 2003. New data on the helminth fauna of rodents of Lithuania. Acta Zoologica Lituanica, 13, 41-47. DOI: 10.1080/13921657.2003.10512542

McCoy K., Boulinier T., Tirard C., Michalakis Y. 2003. Host-dependent genetic structure of parasite populations: differential dispersal of seabird tick host races. Evolution, 57, 288-296. DOI: $10.1111 /$ j.0014-3820.2003.tb00263.x

McCoy K., Boulinier T., Tirard C. 2005. Comparative host-parasite population structures: disantangling prospecting and dispersal in the black-legged kittiwake Rissae tridactyla. Molecular Ecology, 14, 2825-2838. DOI: 10.1111/j.1365-294X.2005.02631.x

Mulvey M., Aho J.M., Lydeard C. 1991. Comparative population genetic structure of a parasite (Fascioloides magna) and its definitive host. Evolution, 45, 1628-1640. DOI: 10.2307/2409784

Nadler S.A., Hafner M.S. 1990. Genetic differentiation among chewing louse populations (Mallaphaga: Trichodectidae) in a pocket gopher contact zone (Rodentia: Geomyidae). Evolution, 44, 942-951

Nieberding C., Morand S., Libois R., Michaux J.R. 2004. A parasite reveals cryptic phylogeographic history of its host. Proceedings of the Royal Society of London. Series B, 271, 25592568. DOI: $10.1098 / \mathrm{rspb} .2004 .2930$

Nieberding C., Libois R., Douady S., Morand S., Michaux J.R. 2005. Phylogeography of a nematode (Heligmosomoides polygyrus) in the western Palearctic region: persistence of northern cryptic populations during ice ages? Molecular Ecology, 14, 765779. DOI: $10.1111 / \mathrm{j} .1365-294 X .2005 .02440 . x$

Nieberding C.M., Olivieri I. 2007. Parasites: proxies for host genealogy and ecology? Trends in Ecology and Evolution, 22, 156-165. DOI: 10.1016/j.tree.2006.11.012

Nieberding C., Durette-Desset M.C., Vanderpoorten A., Casanova J.C., Ribas A., Deffontaine V., Feliu C., Morand S., Libois R., Michaux J.R. 2008. Geography and host biogeography matter for understanding the phylogeography of a parasite. Molecular Phylogenetics and Evolution, 47, 538-554. DOI:10.1016/j.ympev.2008.01.028

Nei M. 1973. Analysis of gene diversity in subdivided populations. Proceedings of the National Academy of Sciences of the United States of America, 70, 3321-3323

Nei M., Tajima F. 1983. Maximum likelihood estimation of the number of nucleotide substitutions from restriction sites data. $\mathrm{Ge}$ netics 105, 207-217

N'Zobadila G. 1994. Biologie d'Heligmosomoides polygyrus polygyrus (Dujardin, 1845) (Nematoda-Trichostrongylina). Comparaison avec les espèces proches et sa sous spéciation américaine. Thèse de Doctorat. Muséum National d'Histoire Naturelle, pp. 183

Petit R.J., Duminil J., Fineshi S., Hampe A., Salvini D., Vendramin G.V. 2005. Comparative organization of chloroplast, mitochondrial and nuclear diversity in plant populations. Molecular Ecology, 14, 689-701. DOI: 10.1111/j.1365-294X.2004.02410.x 
Parker M.A., Spoerke J.M. 1998. Geographic structure of lineage associations in a plant-bacterial mutualism. Journal of Evolutionary Biology, 11, 549-562. DOI: 10.1046/j.1420-9101. 1998.11050549.x

Posada D., Crandall K.A. 1998. Modeltest: testing the model of DNA substitution. Bioinformatics, 14, 817-818. DOI: 10.1093/bioinformatics/14.9.817

Price P.W. 1980. Evolutionary Biology of Parasites. Princeton University Press, Princeton, New Jersey, USA

Ramos-Onsins S.E., Rozas J. 2002. Statistical properties of new neutrality tests against population growth. Molecular Biology and Evolution, 19, 2092-2100

Rogers A.R., Harpending H. 1992. Population growth makes waves in the distribution of pairwise genetic differences. Molecular Biology and Evolution, 9, 552-569

Saitou N., Nei M. 1987. The neighbor-joining method: a new method for reconstructing phylogenetic trees. Molecular Biology and Evolution, 4, 406-425

Schulthesis A.S., Weigt L.A., Hendricks A.C. 2002. Gene flow, dispersal, and nested clade analysis among populations of the stonefly Peltoperla tarteri in the southern Appalachians. Molecular Ecology, 11, 317-327. DOI: 10.1046/j.1365294X.2002.01445.x

Slatkin M., Hudson R.R. 1991. Pairwise comparaisons of mitochondrial DNA sequences in stable and exponentially growing populations. Genetics, 12, 555-562

Spitzenberger F. 1999. Clethrionomys glareolus. In: The Atlas of European Mammals (eds Mitchell-Jones AJ, Amori G, Bogdanowicz. W et al.), Academic Press, London. pp. 212-213

Tajima F. 1989. Statistical method for testing the neutral mutation hypothesis by DNA polymorphism. Genetics, 123, 585-595

Received: July 14, 2014

Revised: August 29, 2014

Accepted for publication: September 9, 2014
Tamura K., Nei M., Kumar S. 2004. Prospects for inferring very large phylogenies by using the neighbor-joining method. Proceedings of the National Academy of Sciences of the United States of America, 101, 11030-11035

Tamura K., Peterson D., Peterson N., Stecher G., Nei M., Kumar S. 2011. MEGA5: Molecular Evolutionary Genetics Analysis using Maximum Likelihood, Evolutionary Distance, and Maximum Parsimony Methods. Molecular Biology and Evolution, 28, 2731-2739. DOI: 10.1093/molbev/msr121

Trewick S.A., Wallis G.P. 2001. Bridging the 'beech-gap': New Zealand invertebrate phylogeography implictes Pleistocen glaciation and Pliocene isolation. Evolution, 55, 2170-2180

Wickström L.M., Haukisalmi V., Varis S., Hantula J., Fedorov V.B., Henttonen H. 2003. Phylogeography of the circumpolar Paranoplocephala arctica species complex (Cestoda: Anoplocephalidae) parasitizing collared lemmings (Dicrostonyx spp.). Molecular Ecology, 12, 3259-3371. DOI: 10.1046/ j.1365-294X.2003.01985.x

Whiteman N.K., Kimball R.T., Parker P.G. 2007. Co-phylogeography and comparative population genetics of the threatened Galápagos hawk and three ectoparasite species: ecology shapes population histories within parasite communities. Molecular Ecology, 16, 4759-4773. DOI: 10.1111/j.1365-294X.2007. 03512.x

Wright S. 1951. The genetical structure of populations. Ann. Eugen., $15,323-354$

Zhigileva O.N. 2011.Correlation between Biodiversity Indices of Small Mammals and Their Helminths in West Siberian Ecosystems. Contemporary Problems of Ecology, 4, 416-422 